\title{
Prevalence and antibiotics susceptibility profiles of Streptococcus pyogenes among pediatric patients with acute pharyngitis at Felege Hiwot Comprehensive Specialized Hospital, Northwest Ethiopia
}

Destaw Kebede ${ }^{1,2^{*}}$, Alemale Admas ${ }^{2}$ and Daniel Mekonnen ${ }^{2,3}$

\begin{abstract}
Background: Streptococcus pyogenes (S. pyogenes) is a Gram positive bacterium which is a leading cause of pharyngitis, skin and soft tissue infection and post streptococcal syndromes. Due to lack of $\beta$-lactamase enzyme production, it was considered universally susceptible to penicillin group and later generation of $\beta$-lactam antibiotics. As such, empirical treatment was common which might leads to development of antibiotics resistance. Therefore, the aims of this study were to determine the prevalence, antibiotics susceptibility profile; and associated factors of S. pyogenes among pediatric patients with acute pharyngitis in Felege Hiwot Comprehensive Specialized Hospital (FHCSH), Northwest Ethiopia.
\end{abstract}

Methods: Hospital based cross-sectional study was carried out on 154 pediatric patients, whose age ranged from 0 to 18 years old using consecutive convenient sampling technique from 1st February to 19th June 2020 at FHCSH. S. pyogenes were identified by throat swab culture on 5\% sheep blood agar with an overnight incubation at $37{ }^{\circ} \mathrm{C}$ in candle jar containing 5\% $\mathrm{CO}_{2}$. Gram stain, catalase test and bacitracin test were used to identify S. pyogenes. Then,the data were entered into EpiData version 3.1 and analyzed by SPSS version 20 software. Finally, stepwise, bivariable and multivariable logistic regressions were carried out for identifyying factors having significant ssociation $(p<0.05)$ with acute pharyngitis.

Results: From the total throat swabs, 14 (9.1\%) with (95\% Cl; 4.5-14.3) were culture positive for S. pyogenes. From these, all isolates were sensitive to penicillin and ampicillin. On the otherhand, 4 (35.7\%), 4 (35.5\%), 3 (21.4\%), 2 (14.3\%), 1 (7.1\%), $7(50.0 \%)$ and 1 (7.1\%) isolates were resistant for ceftriaxone, vancomycin, erythromycin, tetracycline, chloramphenicol, clindamycin and levofloxacin, respectively. The presence of any smoker in home showed significant association with $S$. pyogenes acute pharyngitis. Furthermore, having tender lymphadenopathy and recurrence were clinical predictors for $S$. pyogenes acute pharyngitis $(P<0.05)$.

(Continued on next page)

\footnotetext{
* Correspondence: amaueldestaw@gmail.com

'Shegaw Motta General Hospital, East Gojjam Zone, Motta Town, Ethiopia 2Department of Medical laboratory Science, College of Medicine and Health Sciences, Bahir Dar University, P.O.Box: 79, Bahir Dar, Ethiopia

Full list of author information is available at the end of the article
} 
(Continued from previous page)

Conclusion: The prevalence of S. pyogenes was guaged at 9.1\% which is considered as low prevalence. All S. pyogenes isolats remain sensitive to penicillin. However, resistance was reported to clindamycin 7 (50.0\%), ceftriaxone 5 (35.7\%) and erythromycin 3 (21.4\%). The current practice of giving erythromycin, clindamycin instead of penicillin and ampicillin is againest the microbiology result. Therefore, current empirical treatment of acute pharyngitis shall take in to account the current evidences. Continuous surveillance of antibiotics resistance pattern of S. pyogenes for acute pharyngitis must be strengthen to improve the use of antibiotics in hospitals.

Keywords: Prevalence, S. pyogenes, Pediatrics, Acute pharyngitis, Antibiotics susceptibility test

\section{Background}

Streptococcus pyogenes (S. pyogenes) is a Gram positive, extracellular, spherical shape and $\beta$-hemolytic bacterium which can grow on enrichment culture media [1]. It was identified as the cause of erysipelas in 1883 by Friedrich Fehleisen [2]. However, in 1933, Rebecca Lancefield made serologic classification of Group A Streptococcus (GAS) based on group A carbohydrate that composed of $\mathrm{N}$-acetyl glucosamine linked to $S$. pyogenes cell wall antigens as rhamnose polymer backbone. As the result, GAS was named as S. pyogenes [3].

S. pyogenes were responsible for several clinical conditions such as scarlet fever, acute rheumatic fever, glomerulonephritis, sepsis, necrotizing fasciitis, meningitis, streptococcal toxic shock syndrome, impetigo and acute pharyngitis [4]. Acute pharyngitis is one of the disease caused by $S$. pyogenes. It is an inflammation of oropharynx mucous membranes or posterior pharynx and tonsils [5] with different clinical manifestations such as sore throat, sudden onset fever, red pharynx, enlarged tonsils, yellow or blood-tinged exudates, petechiae on the soft palate and posterior pharynx [6].

About hundred millions people develop serious $S$. pyogenes infection every year. It cause about 660,000 invasive infections and 616 million cases of pharyngitis that result in 163,000 death from 2009 to 2014 [7]. In African countries, S. pyogenes was isolated from children with acute pharyngitis and the its' prevalence was as high as 66.7, 28, 2.3, and 11.3\% in Nigeria [8], Egypt [9], Kenya [10] and Jimma, Ethiopia [11], respectively.

S.yogen transmission can be through direct contact, contaminated fomites, or food borne contamination or droplets from those with pharyngeal infection or colonization [12]. Most S. pyogenes infections were treated with penicillin and still being effectively used for emprical treatment [13]. However, those patients with allergic to penicillin have been treated with erythromycin, amoxicillin, cotrimoxazole, chloramphenicol, tetracycline, azithromycin and clindamycin [14]. Hence, current treatment guidelines discourage the empirical use of antibiotics due to unnecessary antibiotic exposure and drug resistance [15].
Additionally, due to lack of $\beta$-lactamase enzyme production by $S$. pyogenes, it was considered universally susceptible to penicillin group and later generation of $\beta$-lactam antibiotics. Even though, early untreated $S$. pyogenes acute pharyngitis leads to post infection complications such as acute rheumatic fever (ARF) and rheumatic heart disease (RHD) and glomerulonephritis [16].

There is not much information on the screening of children for carriage of S. pyogenes in Ethiopia [17] but empirical treatment is the current practice in the study area and at large in Ethiopia. Additionally, people do not complete their treatment or took irregularly. Even though all these practices might contribute for drug resistance emergency in the study area, the study on prevalence, AST and associated factors of S. pyogenes acute pharyngitis among pediatric patients was not done in Amhara region, Bahir Bar. Additionally, empirical treatment is common on acute pharyngitis without any laboratory identification of real pathogens. However, the clinical predictors of acute phayngitis were variable across geographical regions. Therefore, this study aimed to determine the prevalence, antibiotics susceptibility profiles and associated factors of $S$. pyogenes among pediatric patients with acute pharyngitis in $\mathrm{FHCSH}$, Bahir Dar, Northwest Ethiopia.

\section{Methods}

\section{Study design, period, area and population}

Hospital based cross-sectional study was carried out from 1st February to 19th June 2020 at FHCSH in Bahir Dar, Ethiopia.. In FHCSH, there was 121 empirically treated acute pharyngitis cases in the last February to may, 2019 [18]. Padiatric patients attending to $\mathrm{FHCSH}$ with acute pharyngitis were the study population.

\section{Inclusion and exclusion criteria}

All children with age $\leq 18$ years and with symptoms of acute pharyngitis at FHCSH were included to this study. Whereas, those who took antibiotics within 2 weeks of sample collection were excluded in this study. 
Sample size determination and sampling technique

The sample size was calculated using a single population proportion formula based on the assumption of $5 \%$ expected margins of error, 95\% confidence interval $(\mathrm{Za} /$ $2=1.96)$ or alpha $(\alpha=5 \%)$ and $11.3 \%$ prevalence based on a study in Jimma town, Ethiopia [11].

$$
\mathrm{N}=\frac{(\mathrm{Za} / 2)^{2} \times \mathrm{P}(1-\mathrm{P})}{\mathrm{d}^{2}}=\frac{(1.96)^{2} \times 0.113(1-0.113)}{\left(0.05^{2}\right)}=154
$$

where $\mathrm{p}$ - prevalence

d- margin of error

$\mathrm{N}$ - Number of sample size

Thus, a total 154 throat samples were collected by consecutive convenient sampling technique.

\section{Data collection and processing}

The data were collected by trained pediatric nurses and principal investigator. Thus, sociodemographic, environmental factors, behavioral and housing related data were collected by structured pre-tested Amharic version questionnaire using face to face interview with parents/ guardians. Participants whose age $<15$ were interviewed via their gurdian and participants whose age $>15$ years were interviewed directly after obtaining assent. Clinical data were collected by trained pediatric nurses. At each data collection spot, sufficient explanation about the aim of the research was given to the parents or study participants before conducting the interview.

\section{Sample collection and transportation}

A single throat swab specimen was collected on the tonsils and the posterior pharynx from each study participants for culture using sterile cotton swab. The specimen could be collected at symptomatic area at which cotton swab rolled three times on exudates, inflamed pharynx, and swollen tonsil. Tongue depressor was used to depress tongue during throat swab collection [19]. Then, these throat swabs were transported using Amie's transport media with cold box containing ice pack to Bahir Dar University, Microbiology Research Laboratory Center.

\section{Streptococcus pyogenes identification}

Throat swabs were inoculated on $5 \%$ sheep blood agar plates and incubated at $37^{\circ} \mathrm{C}$ in candle jar with $5 \% \mathrm{CO}_{2}$ atmosphere for $24 \mathrm{~h}$ [20-22]. Catalase test was done from $24 \mathrm{~h}$ growth of $\beta$-hemolytic colonies to differentiate catalase negative Streptococcus species. This catalase negative Streptococcus species was subjected to bacitracin test. As such, colony suspension with normal saline matched with 0.5 McFarland standards was prepared from fresh $24 \mathrm{~h}$ growth of colonies and inoculated on $5 \%$ sheep blood agar. Then, imidiately placed bacitracin disk. Finally, any inhibition was showed as bacitracin sensitive for S. pyogenes [20] after $24 \mathrm{~h}$ incubation at $37^{\circ} \mathrm{C}$ in candle jar [19].

\section{Antibiotic susceptibility test}

Antimicrobial susceptibility test (AST) was done by disk diffusion method on Mueller-Hinton (MHA) agar supplemented with $5 \%$ sheep blood [20]. Suspension was prepared from 3 to 5 pure S. pyogenes colonies mixed with $5 \mathrm{ml}$ normal saline in sterile glass test tube which matched with 0.5 McFarland standards. Such suspension was evenly spread onto Mueller Hinton agar supplemented with $5 \%$ sheep blood using sterile cotton swab. The tested antibiotics included penicillin $(P=10 \mathrm{U})$, ampicillin $\quad(\mathrm{AMP}=10 \mu \mathrm{g})$, erythromycin $\quad(\mathrm{E}=15 \mu \mathrm{g})$, chloramphenicol $(\mathrm{C}=30 \mu \mathrm{g})$, clindamycin $(\mathrm{DA}=2 \mu \mathrm{g})$, tetracycline $(\mathrm{TE}=30 \mu \mathrm{g})$, vancomycin $(\mathrm{VA}=30 \mu \mathrm{g})$, levofloxacin $(\mathrm{LEF}=5 \mu \mathrm{g})$, ceftriaxone $(\mathrm{CRO}=30 \mu \mathrm{g})$, cefotaxime $(\mathrm{CTX}=30 \mu \mathrm{g})$, Collect cefepime $(\mathrm{FEP}=30 \mu \mathrm{g})$. After inoculation, it was incubated at $37^{\mathrm{O}} \mathrm{c}$ in a candle jar for over $18 \mathrm{~h}$. After then, zone of inhibition was measured with ruler and interpreted as sensitive, intermediate and resistant according to the principles established by CLSI M100 guideline [20].

\section{Quality control}

The structured questionnaires were prepared in English and translated into Amharic language and then back translated to English to check inconsistencies of meaning of words. About $5 \%$ of structured questionnaire was pretested in Shegaw Motta General Hospital and training was also provided to pediatric nurse how to collect the data.

After throat swab samples were collected aseptically, transportation was carried out using Amies transport medium [22] to Bahir Dar university Microbiology Resaerch Laboratory Center by maintaining cold chain, or cold box with dry ice [23]. The culture media was prepared aseptically by autoclaving and the sterlity was checked by incubating $5 \%$ of the batch prepared media overnight. Additionally, the performance of the media was checked for growth of known Streptococcus pneumoniae (S. pneumoniae) ATCC 49619 as a positive control [20]. Likewise, Bacitracin test was checked by Streptococcus pyogene ATCC 19615 as positive and Streptococcus agalactiae ATCC 13813 as negative control.

\section{Data analysis}

Data was entered by EpiData version 3.1 and data analysis was performed using SPSS version 20. The prevalence of $S$. pyogenes and antibiotics resistance was determined by descriptive statistics. Multivariable logistic regression was done by entering the variables with 
$p<0.2$ in bivariable logistic regression to identify the associated factor and clinical predictors. A P value $<0.05$ considered as statistically significant association in the multivariate logistic regression.

\section{Ethical consideration}

The study approved by College of Medicine and Health Science, Bahir Dar University's Research Institutional Review Board with reference number CMHS 0014/2020 and a permission letter was obtained from FHCSH. The purpose and importance of the study was explained to the participants. Written informed consent from parent/guardian and assent from children was obtained in accordance with the Declaration of Helsinki. Additionally, absence of link between the study and their service was explained and participation was entirely voluntary based. Furthermore, the confidentiality of study participant was kept and identification of study participant by name was avoided.

\section{Results}

Sociodemographic characteristics of study participants A total of 154 pediatric children were recruited to this study. From those, the majority 81 (52.6\%) of participants were females and $73(47.4 \%)$ were males. Study participant's age were ranged from 0 to 18 years old with mean age 8.483, median 9.0 and standard deviation $(\mathrm{SD}=4.8)$. Majority of study participants were less than 5 years age 51 (33.1\%) followed by $5-10$ years of age 46 (29.9\%) and 10-15 years of age 43 (27.9\%). Moreover, about $102(66.2 \%)$ participants were from urban. Additionally, the majority $65(42.1 \%)$ of participants could not able to read \& write (Table 1 ).

\section{Prevalence of Streptococcus pyogenes}

The overall prevalence of $S$. pyogenes was 14 (9.1\%; 95\%; $\mathrm{CI}=4.5-14.3)$. Out of the total S. pyogenes culture positives with acute pharyngitis, females shared 11 (7.1\%). According to age categories, there was no positive for $S$. pyogenes in the age less than 5 years. Whereas $8(5.2 \%)$, $5(3.2 \%)$ and $1(0.7 \%)$ were age between 5 and $10,10-15$ and $15-18$, respectively. Furthermore, about 8 (5.2\%) $S$. pyogenes isolates were isolated from those participants in primary school. The isolation rates of $S$. pyogenes with different socio-demographic characteristics were summarized (Table 1).

\section{Antibiotics susceptibility profiles of Streptococcus pyogenes}

Different antibiotics classes were used for determining susceptibility profile of S. pyogenes isolates. As the result,

Table 1 Prevalence of S. pyogenes with respect to socio-demographic characteristics among pediatric patient with acute pharyngitis in FHCSH, Northwest Ethiopia, 1st February to 19th June 2020

\begin{tabular}{|c|c|c|c|c|}
\hline \multirow[t]{2}{*}{ Variables } & \multirow[t]{2}{*}{ Categories } & \multicolumn{2}{|c|}{ Culture result for S. pyogenes } & \multirow{2}{*}{$\begin{array}{l}\text { Total } \\
\mathrm{N}(\%)\end{array}$} \\
\hline & & $\begin{array}{l}\text { Positive } \\
\text { N (\%) }\end{array}$ & $\begin{array}{l}\text { Negative } \\
\mathrm{N}(\%)\end{array}$ & \\
\hline \multirow[t]{2}{*}{ Sex } & Male & $3(2.0)$ & $70(45.45)$ & $73(47.45)$ \\
\hline & Female & $11(7.1)$ & $70(45.45)$ & $81(52.55)$ \\
\hline \multirow[t]{4}{*}{ Age (in year) } & $<5$ & $0(0)$ & $51(33.1)$ & $51(33.1)$ \\
\hline & $5-9$ & $8(5.2)$ & $38(24.7)$ & $46(29.9)$ \\
\hline & $10-14$ & $5(3.2)$ & $38(24.7)$ & $43(27.9)$ \\
\hline & $15-18$ & $1(0.7)$ & $13(8.4)$ & $14(9.1)$ \\
\hline \multirow[t]{2}{*}{ Residence } & Urban & $9(5.9)$ & $93(60.4)$ & $102(66.3)$ \\
\hline & Rural & $5(3.2)$ & $47(30.5)$ & $52(33.7)$ \\
\hline \multirow[t]{5}{*}{ Education level of children } & Cannot read \&write & $5(3.2)$ & $60(39.1)$ & $65(42.2)$ \\
\hline & Can read \& write & $0(0)$ & $7(4.7)$ & $7(4.7)$ \\
\hline & Primary school & $8(5.2)$ & $56(34.4)$ & $64(41.6)$ \\
\hline & Secondary school & $1(0.6)$ & $16(10.3)$ & $17(10.9)$ \\
\hline & College and above & $0(0)$ & $1(0.6)$ & $1(0.6)$ \\
\hline \multirow[t]{5}{*}{ Occupation of parents/guardians } & House wife & $4(2.65)$ & $42(27.3)$ & $46(29.95)$ \\
\hline & Farmer & $4(2.65)$ & $33(21.4)$ & $37(24.05)$ \\
\hline & Merchant & $3(1.9)$ & $29(18.8)$ & $32(20.7)$ \\
\hline & Laborer & $0(0)$ & $8(5.2)$ & $8(5.2)$ \\
\hline & Employed & $3(1.9)$ & $28(18.2)$ & $31(20.1)$ \\
\hline Total & & $14(9.1)$ & $140(90.9)$ & $154(100)$ \\
\hline
\end{tabular}


all isolates of S. pyogenes were sensitive for both penicillin and ampicillin. Furthermore, the proportions of antibiotics resistances to clindamycin, ceftriaxone, cefotaxime, cefepime, vancomycin, erythromycin, tetracycline and chloramphenicol were 7 (50.0\%), 5 (35.7\%), 3 (21.4\%), 2 (14.3\%), 5 (35.7\%), 3 (21.4\%), 2 (14.3\%) and 1 (7.1\%), respectively. However, clindamycin 1 (7.1\%), erythromycin $2(14.3 \%)$, tetracycline $2(14.3 \%)$ and chloramphenicol 2 (14.3\%) were intermediate findings (Fig. 1).

Out of the total $14 S$. pyogene isolates, the proportion of multidrug resistant isolates were $3(21.3 \%)$. From which, $1(7.1 \%)$ was multi drug resistance for erythromycin, clindamycin and vancomycin but $1(7.1 \%)$ for erythromycin, tetracycline and vancomycin. The rest 1(7.1\%) was multidrug resistant for chloramphenicol, Cephame group and levofloxacin simultaneously.

\section{Factors associated with Streptococcus pyogenes acute pharyngitis}

In univariables analysis, variables having a $P$-value of $<$ 0.2 was entered in to multivariable logistic regression analysis. Based on this, sex, number of bed shared in home, frequency of cold drink, presence of smoker in home, separate kitchen and malnutrition were selected by forward likelihood logistic regression method. After adjusting other confounding variables, the pediatric children living with in the presence of any smokers in home showed 7.11 times more likely to develop S. pyogenes acute pharyngitis than those live in absence of any smokers in hone $(\mathrm{AOR}=7.11, \mathrm{CI}=1.694-29.82, P=$ 0.02) (Table 2).

According to clinical predictors, all variables having a $P$-value $<0.2$ in the bivariable was also subjected to multivariable analysis. Hence, the presence of tender lymphadenopathy were 14.45 times more likely to be $S$. pyogenes acute pharyngitis compared to those did not have tender lymphadenopathy $(\mathrm{AOR}=14.45,95 \% \mathrm{CI}=$ 1.6-30.3, $P=0.03)$. Similarly, the pediatric patients with history of recurrence were 5.87 time more likely to be acute pharyngitis caused by $S$. pyogenes compared to those did not having recurrence $(\mathrm{AOR}=5.87,95 \% \mathrm{CI}=$ 1.63-12.31, $P=0.02$ ). Therefore, tender lymphadenopathy and history of clinical recurrence $(P<0.05)$ were found to be independent predictors for $S$. pyogenes acute pharyngitis in pediatrics (Table 3 ).

\section{Discussion}

Streptococcus pyogenes infection among the pediatric group is a cause of acute pharyngitis which could leads morbidity and mortality [24]. Pediatric patients with acute pharyngitis require microbiologic investigation and proper treatment to abort complications [25]. A totals of 154 throat swab samples were analyzed in the present study. Our 95\% CI (4.5-14.3) used to clasfied studies in to low and high prevalence. For instance, prevalence studies with $<4.5 \%$ were considered as lower, and prevalence studies with $>14.3 \%$ is considered as higher findings and findings in between 95\% CI of our study were considered as in agreement with current study.

Accordingly, the prevalence of S. pyogenes 14.9.1\%) in the current study which is comparable with the previous conducted in Jimma, Ethiopia 11.3\% [11], India 5.5\% [16], Japan 5.8\% [26], Indonesia 13.5\% [27] and Nepal $9.2 \%$ [28]. But it was higher than a study from Mexico $0.04-0.42 \%$ [29], Brazil 3.9\% [30], Romania 4\% [31], Iran2.5\% [32] and Saudi Arabia 1.5\% [33]. This high prevalence rate in our study might be due seasonal nature of S. pyogenes incidence which is higher from February to May [11]. Additional reason for the difference

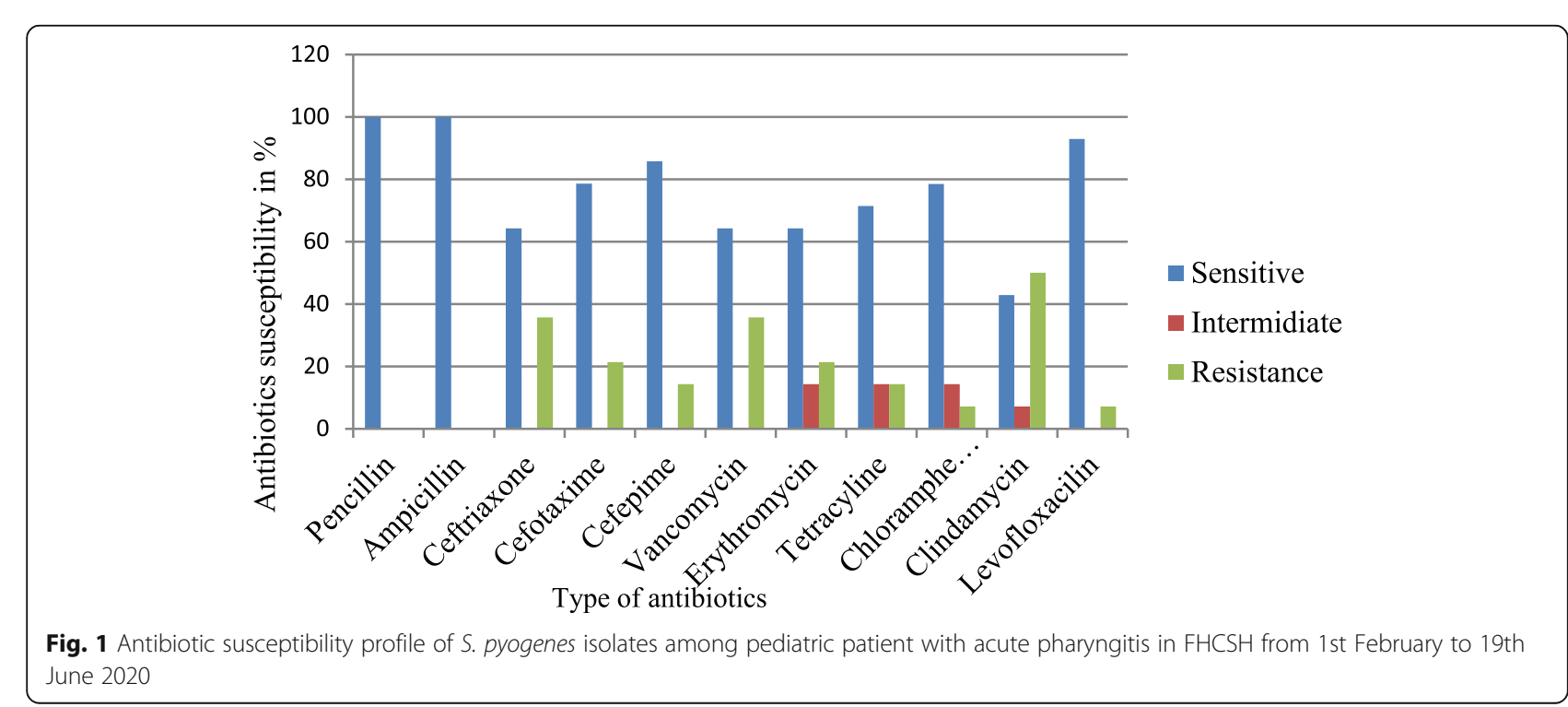


Table 2 Bivariable and multivariable logistic regression analysis of factors associated with S. pyogenes acute pharyngitis in FHCSH, Northwest Ethiopia, 1st February to 19th June 2020

\begin{tabular}{|c|c|c|c|c|c|}
\hline \multirow[t]{2}{*}{ Variables } & \multirow[t]{2}{*}{ Categories } & \multicolumn{2}{|c|}{ S. pyogenes } & \multirow[t]{2}{*}{ COR(95\%Cl) $P$ - value } & \multirow[t]{2}{*}{ AOR $(95 \% \mathrm{Cl}) P$ - value } \\
\hline & & Pos (N) & $\operatorname{Neg}(\mathrm{N})$ & & \\
\hline \multirow[t]{2}{*}{ Family number in home } & $\geq 5$ & 13 & 75 & $11.2(1.4-88.5) 0.021^{*}$ & - \\
\hline & $<5$ & 1 & 65 & 1 & \\
\hline \multirow[t]{2}{*}{ Sex } & Male & 3 & 70 & 1 & - \\
\hline & Female & 11 & 70 & 3.66 (2.98-13.71) $0.054^{*}$ & \\
\hline \multirow[t]{4}{*}{ Age (in year) } & $<5$ & 0 & 51 & $3.92(1.24-67.0) 0.35$ & - \\
\hline & $5-10$ & 8 & 38 & $1.42(1.05-3.72) 0.434$ & \\
\hline & $10-15$ & 5 & 38 & $1.59(1.06-5.450) 0.63$ & \\
\hline & $>15$ & 1 & 13 & 1 & \\
\hline \multirow[t]{2}{*}{ Residence } & Urban & 9 & 93 & 1 & - \\
\hline & Rural & 5 & 47 & $1.09(0.35-3.47) 0.872$ & \\
\hline \multirow[t]{2}{*}{ Number of bed shared in home } & $>2$ & 2 & 72 & $6.35(1.37-29.43) 0.018^{*}$ & - \\
\hline & $\leq 2$ & 12 & 68 & 1 & \\
\hline \multirow[t]{2}{*}{ Frequently cold Drink } & Yes & 8 & 41 & $3.22(1.05-9.86) 0.041^{*}$ & - \\
\hline & No & 6 & 99 & 1 & \\
\hline \multirow[t]{2}{*}{ Passive Smoker } & Yes & 8 & 30 & $4.89(1.57-15.18) 0.006^{*}$ & $7.11(1.69-29.82) 0.01^{* *}$ \\
\hline & No & 6 & 110 & 1 & 1 \\
\hline \multirow[t]{2}{*}{ Active smoker } & yes & 1 & 23 & $2.56(1.32-20.51) 0.38$ & - \\
\hline & No & 13 & 117 & 1 & \\
\hline \multirow[t]{2}{*}{ Separate kitchen } & Yes & 3 & 73 & $1.07(1.01-3.55) 0.012^{*}$ & $2.05(1.21-5.45) 0.16$ \\
\hline & No & 11 & 67 & 1 & 1 \\
\hline \multirow[t]{2}{*}{ Malnutrition } & Yes & 1 & 4 & $2.12(1.07-19.10) 0.06^{*}$ & - \\
\hline & No & 13 & 136 & & \\
\hline
\end{tabular}

$N$ Frequency, COR Crude odd Ratio, AOR Adjusted Odd Ratio, Pos Positive, Neg Negative, ${ }^{*}=$ variable enrolled to multivariate regression $(P$ - value $<0.2)$,

${ }^{* *}=$ statistical significant

might be sample size and method variation. In the contrary, the proportion of the recent study $9.1 \%$ was much lower than findings from USA $28.6-37 \%[34,35]$ and $16-45 \%$ in African [36-39], Iran 30\% [40] and Israel $69.5 \%$ [41]. Such variation could be attributed to difference geography, method, socio-economic conditions, and sample size.

Based on antibiotics susceptibility profiles in the present study, all isolates were sensitive to penicillin which is in agreement with studies reported in USA [29, 30], Asia [16, 42, 43], Europe [41, 44, 45], African countries including Egypt [46], Kenya [39] and Jima, Ethiopia [11]. This might be due to lack of $\beta$-lactamase production by $S$. pyogenes. Even though, penicillin resistance for S. pyogenes may happen by escaping penicillin treatment by entering epithelial cells, which are poorly penetrated by penicillin [47], by forming a biofilm [48] and protection of $S$. pyogenes by other $\beta$-lactamase-producing bacterial species $[49,50]$.

In accordance to other antibiotic resistance, simple comparison of resistance percentage was done comparatively, which was statistically higher or lower than those reported in the previous studies. Hence, it is known that erythromycin and clindamycin are usually used as an alternative treatment for patients allergic to penicillin. However, in the current study, erythromycin (21.4\%) and clindamycin $(50 \%)$ resistance were recorded which was higher than no resistant to erythromycin and clindamycin reported in Jimma, Ethiopia [11], erythromycin (10.6\%) in Spain [45] but much lower than $64-83 \%$ resistance to erythromycin in India [43, 51]. Similarly, 35.7, 21.4 and $14.3 \%$ resistance to ceftriaxone, cefotaxime and cefepime were reported in our study which was higher than no resistance for ceftriaxone and cefotaxime in Pakistan [42] and India [16, 43] and Ethiopia [11], respectively. This variation might be due to physician provided treatment of non $\beta$-lactam drugs for acute pharyngitis case by considering Gram negative bacteria empirically. This might be the leading cause a high rate cephalosporin and erythromycin resistance. Additionally, erythromycin resistance in S. pyogenes occurs via target site modification that erythromycin ribosomal methylase (erm) genes encode an enzyme that methylate a single adenine in $23 \mathrm{~S}$ rRNA and results 
Table 3 Bivariable and multivariable logistics regression analysis of chief clinical variables for S. pyogenes acute pharyngitis in FHCSH, Northwest Ethiopia, 1st February to 19th June 2020

\begin{tabular}{|c|c|c|c|c|c|}
\hline \multirow[t]{2}{*}{ Variables } & \multirow[t]{2}{*}{ Category } & \multicolumn{2}{|c|}{ S. pyogenes } & \multirow{2}{*}{$\begin{array}{l}\text { COR }(95 \% \mathrm{Cl}) P \\
\text { value }\end{array}$} & \multirow[t]{2}{*}{ AOR $(95 \% \mathrm{Cl}) P$ value } \\
\hline & & Pos (N) & Neg (N) & & \\
\hline \multirow[t]{2}{*}{ Body temperature $\left(\ln { }^{\circ} \mathrm{C}\right)$} & $\geq 38$ & 4 & 31 & $2.41(1.41-8.79) 0.57$ & \\
\hline & $<38$ & 10 & 109 & 1 & \\
\hline \multirow[t]{2}{*}{ Painful throat } & Yes & 13 & 121 & $2.04(1.25-16.51) 0.50$ & \\
\hline & No & 1 & 19 & 1 & \\
\hline \multirow[t]{2}{*}{ Headache } & Yes & 6 & 65 & $1.16(1.08-3.50) 0.79$ & - \\
\hline & No & 8 & 75 & 1 & \\
\hline \multirow[t]{2}{*}{ Vomiting } & Yes & 2 & 33 & $1.85(1.94-8.69) 0.44$ & - \\
\hline & No & 12 & 107 & 1 & \\
\hline \multirow[t]{2}{*}{ Abdominal pain } & Yes & 1 & 18 & $1.92(1.24-15.56) 0.54$ & \\
\hline & No & 13 & 122 & 1 & \\
\hline \multirow[t]{2}{*}{ Enlarged tonsil } & Yes & 8 & 75 & $1.86(1.38-3.50) 0.80$ & - \\
\hline & No & 6 & 65 & 1 & \\
\hline \multirow[t]{2}{*}{ Recurrence } & Yes & 11 & 54 & $5.84(1.56-21.87) 0.01^{*}$ & $5.87(1.89-26.78) 0.02^{* *}$ \\
\hline & No & 3 & 86 & 1 & 1 \\
\hline \multirow[t]{2}{*}{ Inflame pharynx } & Yes & 9 & 87 & $1.10(1.349-3.45) 0.88$ & - \\
\hline & No & 5 & 53 & 1 & \\
\hline \multirow[t]{2}{*}{ Pharyngeal Exudate } & Yes & 12 & 84 & $4.0(1.86-18.56) 0.08^{*}$ & - \\
\hline & No & 2 & 56 & 1 & \\
\hline \multirow[t]{2}{*}{ Lymphadenopathy } & Yes & 13 & 71 & $1.83(1.6-5.56) 0.029^{*}$ & $14.45(1.6-30.3) 0.02^{* *}$ \\
\hline & No & 1 & 69 & 1 & 1 \\
\hline \multirow[t]{2}{*}{ Scarlatiniform Rash } & Yes & 10 & 41 & $12.6(1.61-99.2) 0.02^{*}$ & - \\
\hline & No & 4 & 99 & 1 & \\
\hline \multirow[t]{2}{*}{ Dysphagia } & Yes & 10 & 79 & $1.93(1.58-6.45) 0.29$ & - \\
\hline & No & 4 & 61 & 1 & \\
\hline \multirow[t]{2}{*}{ Running nose } & Yes & 2 & 25 & $1.3(1.28-6.20) 0.74$ & - \\
\hline & No & 12 & 115 & 1 & \\
\hline
\end{tabular}

$N$ frequency, COR Crude odd Ratio, AOR Adjusted Odd Ratio, Pos Positive, Neg Negative, ${ }^{*}=$ variable entered to multivariate regression $(P$ - value $<0.2)$,

** $=$ statistical significant

conformational change in the ribosome, leading to reduced binding of erythromycin and clindamycin [52]. Similarly, in target drug efflux, mefA (macrolide efflux pump) genes encode an efflux pump of 14- and 15-carbonring macrolides, conferring resistance to erythromycin only. Furthermore, tetracycline resistance is conferred by ribosome protection genes such as tet $(\mathrm{M})$ or tet $(\mathrm{O})$ and efflux pumps for tetracycline encoded by the tet $(\mathrm{K})$ or tet $(\mathrm{L})$ gene also confer tetracycline resistance [53]. The erm and mefA genes are often collocated with tet gene of $S$. pyogenes strains are resistant to both macrolides and tetracycline [54].

According to factors in the current study, presence of any smokers in home $(P$ value $<0.05)$ was associated with $S$. pyogenes acute pharyngitis in pediatric patients. This result was in agreement with previous finding reported in Northern India [44]. This might be due to presence of any smoker in home leads to children inhaled smokes which kills normal flora that able to compete pathogen from adherence, altered bacterial acquisition and make oral mucosal colonization in favor of $S$. pyogenes periodontal pathogens. Furthermore, the presence tender lymphadenopathy and recurrence $(P$ value $<0.05$ ) were found to be independent clinical predictors for $S$. pyogenes acute pharyngitis among pediatrics. Similar finding of tender lymphadenopathy and recurrences were reported in India [55], Yemen Saudi Arabia [56] and Jimma, Ethiopia [11]. However, clinical predictors varied with geographical area and immune status of study population [57].

\section{Limitation of the study}

The limitations of this study were being small sample size which might be underestimating the prevalence of $S$. pyogenes. Additionally, MIC or E test was not done 
for better evaluation of its antibiotics susceptibility profiles.

\section{Conclusion}

In this study, the prevalence of $S$. pyogenes in pediatric children with acute pharyngitis was $9.1 \%$. All S. pyogenes remain sensitive to penicillin and ampicillin. The resistance rate was obtained to clindamycin 7 (50.0\%), ceftriaxone 5 (35.7\%), vancomycin 5 (35.7\%), cefotaxime 3 (21.4\%), erythromycin $3(21.4 \%)$, cefepime $2(14.3 \%)$ and tetracycline $2(14.3 \%)$. The overall multidrug resistance was $21.3 \%$. Relatively low resistance was documented to penicillin, ampicillin, levofloxacin and chloramphenicol. Hence, similar to other studies these drugs were considered as an empirical treatment for S. pyogenes acute pharyngitis in pediatric patients. The presence of any smoker in home was associated with $S$. pyogenes acute pharyngitis whereas tender lymphadenopathy and recurrence of sore throat were clinical predictors for $S$. pyogenes acute pharyngitis $(p<0.05)$ in our study. There should be routine throat culture and a continuous surveillance of antibiotics resistance pattern for $S$. pyogenes to improve the use of antibiotics in hospitals.

\begin{abstract}
Abbreviations
ANRSHB: Amhara National Regional State Health Bureau; AOR: Adjusted Odd Ratio; APHI: Amhara Public health Institute; ARF: Acute Rheumatic Fever; AST: Antibiotic Susceptibility Test; ATCC: American Type Culture Collection; BAP: Blood agar plate; BDU: Bahir Dar University; CLSI: Clinical Laboratory of Standard Institute; CMHS: College of Medicine and Health Science; COR: Crude Odd Ratio; FHCSH: Felege Hiwot Comprehensive Specialized Hospital; GAS: Group A Streptococcus; IDSA: Infectious Diseases Society of America; ID: Individual identity; IQC: Internal Quality Control; MHA: MullerHinton agar; MIC: Minimum inhibitory concentration; OPD: Outpatient department; PYR: Pyrrolidonyl arylamidase test; RHD: Rheumatic heat disease; RADT: Rapid antigen detection test; SOPs: Standard operating procedures; SPSS: Statistical package for social sciences; URTI: Upper respiratory tract infection; US: United States; WHO: World Health Organization
\end{abstract}

\section{Acknowledgements}

We would like to forward our gratitude to Bahir Dar University, College of Medicine and Health Sciences, School of Health Sciences, Department of Medical Laboratory Science for providing us the ethical clearance letter. Then we would like to acknowledge all the children, parents and FHCSH paediatric staff who cooperated with us in this study. Finally, we would like to extend our deepest gratitude for ANRSHB for its sponsor and APHI for their logistic support.

\section{Authors' contributions}

Destaw Kebede: Participated on the conception, design, data collection, analysis and interpretation. Daniel Mekonnen and Alemale Admas facilitated the data collection and management, drafted, analysis and critically reviewed the manuscript. All authors read and approved of the final manuscript.

\section{Authors' information}

Destaw Kebede is Laboratory personnel at Shegaw Motta General Hospital in Medical Microbiology. Daniel Mekonnen is an associate professor at College of Medicine and Health Sciences, Bahir Dar University in Medical Microbiology and Institute of Biotechnology, Bahir Dar University, Alemale Admas is lecturer at College of Medicine and Health Sciences, Bahir Dar University in Medical Microbiology.

\section{Funding}

Not applicable.

\section{Availability of data and materials}

The data supporting the conclusion of the study could be avaliabale upon the request of Destaw Kebede (correspondence author; mobile + 251911594675, email: amaueldestaw@gmail.com).

\section{Declarations}

\section{Ethics approval and consent to participate}

The study was approved by College of Medicine and Health Science, Bahir Dar University's research Institutional Review Board (Reference number CMHS 0014/2020) and a permission letter was also obtained from FHCSH. Additionally, informed written consents from guardians or parents and assents from each study participants were obtained in accordance with the Declaration of Helsinki. The confidentiality of study participant was kept and identification of study participant by name was avoided. Positive individuals were linked to health institution for better managements accordingly.

\section{Consent for publication}

Not applicable.

\section{Competing interests}

The authors declare that they have no competing interests.

\section{Author details}

${ }^{1}$ Shegaw Motta General Hospital, East Gojjam Zone, Motta Town, Ethiopia. ${ }^{2}$ Department of Medical laboratory Science, College of Medicine and Health Sciences, Bahir Dar University, P.O.Box: 79, Bahir Dar, Ethiopia. ${ }^{3}$ Biotechnology Research Institute, Bahir Dar University, Bahir Dar, Ethiopia.

Received: 13 January 2021 Accepted: 14 April 2021

Published online: 03 May 2021

\section{References}

1. Walker MJ, Barnett TC, MCArthur JD, Cole JN, Gillen CM, Henningham A, et al. Disease manifestations and pathogenic mechanisms of group a Streptococcus. Clin Microbiol Rev. 2014;27(2):264-301. https://doi.org/10.112 8/CMR.00101-13.

2. Ferretti J, Stevens D.\& Fischetti, V. Laboratory diagnosis of Streptococcus pyogenes (group a streptococci)--Streptococcus pyogenes: Basic Biology to Clinical Manifestations; 2016.

3. Ralph AP, Carapetis JR. Group A Streptococcal Diseases and Their Global Burden. In: Chhatwal G. (eds) Host-Pathogen Interactions in Streptococcal Diseases. Current Topics in Microbiology and Immunology. Springer: Berlin, Heidelberg; 2012. p. 368. https://doi.org/10.1007/82_2012_280

4. Sims Sanyahumbi A, Colquhoun S, Wyber R, et al. Global Disease Burden of Group A Streptococcus. In: Ferretti JJ, Stevens DL, Fischetti VA, editors. Streptococcus pyogenes : Basic Biology to Clinical Manifestations [Internet]. Oklahoma City (OK): University of Oklahoma Health Sciences Center; 2016-. Available from: https://www.ncbi.nlm.nih.gov/sites/books/NBK333415/.

5. Hurst JR, Kasper KJ, Sule AN, McCormick JK. Streptococcal pharyngitis and rheumatic heart disease: the superantigen hypothesis revisited. Infect Genet Evol. 2018;61:160-75. https://doi.org/10.1016/.meegid.2018.03.006.

6. Choby BA. Diagnosis and treatment of streptococcal pharyngitis. Am Acad Fam Phys. 2009;79(5):383-90.

7. Imöhl M, Fitzner C, Perniciaro S, van der Linden M. Epidemiology and distribution of 10 superantigens among invasive Streptococcus pyogenes disease in Germany from 2009 to 2014. PLoS One. 2017:12(7):e0180757.

8. Uzodimma CC, Dedeke Fl, Nwadike V, Owolabi O, Arifalo G.\& Oduwole O. A study of group a streptococcal pharyngitis among 3-15-year-old children attending clinics for an acute sore throat. Niger J Cardiol. 2017;14(2):97. https://doi.org/10.4103/njc.njc_14_17.

9. Sultan A, Seliem W. Evaluating the use of dedicated swab for rapid antigen detection testing in group a streptococcal pharyngitis in children. Afr J Clin Exp Microbiol. 2018;19(1):24-9.

10. Osowicki J, Azzopardi Kl, Baker C, Waddington CS, Pandey M, Schuster T, et al. Controlled human infection for vaccination against Streptococcus pyogenes (CHIVAS): establishing a group a Streptococcus pharyngitis human infection study. Vaccine. 2019:37(26):3485-94. https://doi.org/10.101 6/j.vaccine.2019.03.059. 
11. Tesfaw G, Kibru G, Mekonnen D, Abdissa A. Prevalence of group A $\beta$ hemolytic Streptococcus among children with pharyngitis in Jimma town Southwest Ethiopia. Egypt J Ear, Nose, Throat Allied Sci. 2015;16(1):35-40.

12. Makthal N, VanderWal AR, Saavedra MO, Olsen RJ, Musser JM, Kumaraswami M. Environmental pH and peptide signaling control virulence of Streptococcus pyogenes via a quorum-sensing pathway. Nat Commun. 2019;10(1):1-14.

13. Shulman ST, Bisno AL, Clegg HW, Gerber MA, Kaplan EL, Lee G, et al. Clinical practice guideline for the diagnosis and management of group a streptococcal pharyngitis: 2012 update by the Infectious Diseases Society of America. Clin Infect Dis. 2012;55(10):e86-e102. https://doi.org/10.1093/cid/cis629.

14. Behnamfar Z, Shahkarami V, Sohrabi S, Aghdam AS, Afzali H. Cost and effectiveness analysis of the diagnostic and therapeutic approaches of group a Streptococcus pharyngitis management in Iran. J Fam Med PrimCare. 2019;8(9):2942-9. https://doi.org/10.4103/jfmpc.jfmpc_487_19.

15. Luo R, Sickler J, Vahidnia F, Lee Y-C, Frogner B, Thompson M. Diagnosis and Management of Group a streptococcal pharyngitis in the United States, 20112015. BMC Infect Dis. 2019;19(1):193. https://doi.org/10.1186/s12879-019-3835-4.

16. Khandekar A. Tackling rheumatic heart disease: prevalence and antibiogram of Streptococcus pyogenes in cases of paediatric pharyngitis. J Clin Diagn Res. 2019;13(2):11-3.

17. Abdissa A, Asrat D, Kronvall G, Shitu B, Achiko D, Zeidan M. ... \& Aseffa, A. throat carriage rate and antimicrobial susceptibility pattern of group a streptococci (GAS) in healthy Ethiopian school children. Ethiop Med J. 2011; 49(2):125-30.

18. Fentahun $N$, Anteneh $Y$, Menber $Y$. Malnutrition in the Outcome of Wound Healing at Public Hospitals in Bahir Dar City, Northwest Ethiopia: A Prospective Cohort Study. J Nutr Metab. 2021;2021.

19. World Health Organization (WHO). Guidelines for the collection of clinical specimens during field investigation of outbreaks (No. WHO/CDS/CSR/EDC) 2000.4). Geneva: World Health Organization; 2000. p. 1-54.

20. Clinical Laboratory of Standard Institute (CLSI). Performance standard for antimicrobial susceptibility testing for streptococci spp beta -hemolytic bacteria. 29th edition, CLSI guideline. CLSI Standard M100- Wayne. 2019;39(1):87-95.

21. Gheni Al. Detection of streptococci in the throat swabs from upper respiratory tract infections in Kurdistan region. J Life Sci. 2014;8(3):283-9.

22. Cheesbrough, M. District laboratory practice in tropical countries. part 2, second edtion. 3 chapters. Cambridge Uuniversity Press; 2006. p. 31-45. https://books.google.com.et/books?hl=en\&lr=\&id=Yjv-n5u6S7gC\&oi= fnd\&pg=PA1\&ots=GEoMxt5Jsu\&sig=qdgaLv5dqClpY7I-zbUeefRUvG4\&redir_ esc $=\mathrm{y} \# \mathrm{v}=$ onepage $\& \mathrm{q} \& \mathrm{f}=\mathrm{false}$.

23. Daum L, Worthy SA, Yim KC, Nogueras M, Schuman R, Choi Y, et al. A clinical specimen collection and transport medium for molecular diagnostic and genomic applications. Epidemiol Infect. 2011;139(11):1764-73. https:// doi.org/10.1017/S0950268810002384.

24. Grivea IN, Syrogiannopoulos GA, Michoula AN, Gazeti G, Malli E, Tsilipounidaki K, et al. emm Types and clusters and macrolide resistance of pediatric group A streptococcal isolates in Central Greece during 20112017. PloS one. 2020;15(5):e0232777.

25. Patel C, Green BD, Batt JM, Kholmurodova F, Barnes M, Geyer WJ, et al. Antibiotic prescribing for tonsillopharyngitis in a general practice setting: can the use of modified centor criteria reduce antibiotic prescribing? Aust J Gen Pract. 2019;48(6):395-401. https://doi.org/10.31128/AJGP-08-18-4685.

26. Igarashi $\mathrm{H}$, Nago N, Kiyokawa $\mathrm{H}$, Fukushi M. Abdominal pain and nausea in the diagnosis of streptococcal pharyngitis in boys. Int J Gen Med. 2017;10: 311-8. https://doi.org/10.2147/IJGM.S144310.

27. Malino IY, Utama DL, Soenarto Y. Mclsaac criteria for diagnosis of acute group-a $\beta$-hemolytic streptococcal pharyngitis. Paediatr Indones. 2013;53(5): 258-63. https://doi.org/10.14238/pi53.5.2013.04.

28. Rijal K, Dhakal N, Shah R, Timilsina S, Mahato P, Thapa S, et al. Antibiotic susceptibility of group a Streptococcus isolated from throat swab culture of school children in Pokhara, Nepal. Nepal Med Coll J. 2009;11(4):238-40.

29. Gutiérrez-Jiménez J, Mendoza-Orozco MI, Vicente-Serrano A, Luna-Cazáres LM, Feliciano-Guzmán JM, Girón-Hernández JA, et al. Virulence genes and resistance to antibiotics of beta-hemolytic streptococci isolated from children in Chiapas, Mexico. J Infect Dev Ctries. 2018;12(02):80-8. https://doi. org/10.3855/jidc.9679.

30. Alexandre M, Wang'ondu R, Cooney LM Jr. Focus: infectious diseases: group a streptococcal bacteremia following streptococcal pharyngitis in an older patient with diabetes: a case report. Yale J Biol Med. 2017;90(2):337-40.

31. Bobia AA, Blaj OA, Oancea D, Iulia-Cristina B, Radu-Vasile B, Delia-loana H, et al. The prevalence of beta hemolytic Streptococcus in a Children's
Tertiary Care Hospital in Timisoara. Central Eur J Clin Res. 2019;2(1):73-8. https://doi.org/10.2478/cejcr-2019-0011.

32. Khosravi AD, Ebrahimifard N, Shamsizadeh A, Shoja S. Isolation of Streptococcus pyogenes from children with pharyngitis and emm type analysis. J Chin Med Assoc. 2016;79(5):276-80. https://doi.org/10.1016/j. jcma.2016.01.002.

33. Ashgar SS, Johargy A, Mukhtar M, Saati A. Prevalence of Streptococcus pyogenes among pre-school children ages 4 to 6 in Makah city, Saudi Arabia. Med Sci Healthc J. 2015;10(6):2-18.

34. Shaikh N, Leonard E, Martin JM. Prevalence of streptococcal pharyngitis and streptococcal carriage in children: a meta-analysis. Pediatrics. 2010;126(3): e557-64. https://doi.org/10.1542/peds.2009-2648.

35. Tartof SY, Reis JN, Andrade AN, Ramos RT, Reis MG, Riley LW. Factors associated with group a Streptococcus emm type diversification in a large urban setting in Brazil: a cross-sectional study. BMC Infect Dis. 2010;10(1): 327. https://doi.org/10.1186/1471-2334-10-327.

36. Ali AA, Khater WS, El Gendy YG. Erythromycin resistance in Streptococcus Pyogenes causing pharyngotonsillitis in Egyptian children and its association with the presence of fibronectin binding protein F1 (prtf1) gene. Egypt Jo Med Microbiol. 2016;38(79):1-8.

37. Engel ME, Cohen K, Gounden R, Kengne AP, Barth DD, Whitelaw AC, et al. The Cape Town clinical decision rule for streptococcal pharyngitis in children. Pediatr Infect Dis J. 2017;36(3):250-5. https://doi.org/10.1097/INF. 0000000000001413

38. Madeira G, Chicavel D, Munguambe A, Langa J, Mocumbi A. Streptococcal pharyngitis in children with painful throat: missed opportunities for rheumatic heart disease prevention in endemic area of Africa. Cardiovasc Diagn Ther. 2017;7(4):421.

39. Kunga. Prevalence and antibiotic susceptibility pattern of group a streptococcus in children with acute pharyngitis. In: Doctoral Dissertation, University of Nairobi; 2018. p. 1-59.

40. Sayyahfar S, Fahimzad A, Naddaf A, Tavassoli S. Antibiotic susceptibility evaluation of group A streptococcus isolated from children with pharyngitis: a study from Iran. Infect Chemother. 2015:47(4):225-30. https://doi.org/10.3 947/ic.2015.47.4.225.

41. Chazan B, Raz R, Edelstein H, Kennes Y, Gal V, Colodner R. Susceptibility of group A streptococcus to antimicrobial agents in northern Israel: a surveillance study. Microb Drug Resist. 2015;21(5):551-5. https://doi.org/10.1 089/mdr.2015.0040

42. Bilal M, Zahid M, Aslam Z, Khalid A. Prevalence of Group A beta-haemolytic Streptococcus pharyngitis and drug resistance in community-acquired pharyngitis in Pakistan. Elixir Int J. 2015;89:36831-4.

43. Kumar AS. Is group a b-haemolytic streptococcus prevalent among the children with tonsillo-pharyngitis? A school health survey based study in Pondicherry. J Evid Based Med Health Care. 2017:44(5):21720.

44. Nandi S, Kumar R, Ray P, Vohra H, Ganguly NK. Group A streptococcal sore throat in a periurban population of northern India: a one-year prospective study. Bull World Health Organ. 2001;79(6):528-33.

45. Espadas-Maciá D, Macián EMF, Borrás R, Gisbert SP, Bonet JIM. Streptococcus pyogenes infection in paediatrics: from pharyngotonsillitis to invasive infections. Anales Pediatr (English Edition). 2018;88(2):75-81. https://doi. org/10.1016/j.anpede.2017.02.013.

46. Abd El-Ghany SM, Abdelmaksoud AA, Saber SM, Abd El Hamid DH. Group A beta-hemolytic streptococcal pharyngitis and carriage rate among Egyptian children: a case-control study. Ann Saudi Med. 2015;35(5):377-82. https:// doi.org/10.5144/0256-4947.2015.377.

47. Kaplan EL, Chhatwal GS, Rohde M. Reduced ability of penicillin to eradicate ingested group a streptococci from epithelial cells: clinical and pathogenetic implications. Clin Infect Dis. 2006;43(11):1398-406. https://doi. org/10.1086/508773

48. Ogawa T, Terao Y, Okuni H, Ninomiya K, Sakata H, Ikebe K, et al. Biofilm formation or internalization into epithelial cells enable Streptococcus pyogenes to evade antibiotic eradication in patients with pharyngitis. Microbiol Pathog. 2011;51(1-2):58-68

49. Brook I, Gober AE. Failure to eradicate streptococci and beta lactamase producing bacteria. Acta Paediatr. 2008;97(2):193-5. https://doi.org/10.1111/ j.1651-2227.2007.00610.x

50. Brook I. Penicillin failure in the treatment of streptococcal pharyngotonsillitis. Curr Infect Dis Rep. 2013;15(3):232-5. https://doi.org/10.1007/s11 908-013-0338-0. 
51. Berwal A, Chawla K, Shetty S, Gupta A. Trend of antibiotic susceptibility of Streptococcus pyogenes isolated from respiratory tract infections in tertiary care hospital in South Karnataka. Iran J Microbiol. 2019;11(1):13-8.

52. Clancy J, Petitpas J, Dib-Hajj F, Yuan W, Cronan M, Kamath AV, et al. Molecular cloning and functional analysis of a novel macrolide-resistance determinant, mefA, from Streptococcus pyogenes. Mol Microbiol. 1996;22(5): 867-79. https://doi.org/10.1046/j.1365-2958.1996.01521.x.

53. Richter SS, Heilmann KP, Beekmann SE, Miller NJ, Miller AL, Rice CL, et al. Macrolide-resistant Streptococcus pyogenes in the United States, 2002-2003. Clin Infect Dis. 2005;41(5):599-608. https://doi.org/10.1086/432473.

54. Chopra I, Roberts M. Tetracycline antibiotics: mode of action, applications, molecular biology, and epidemiology of bacterial resistance. Microbiol Mol Biol Rev. 2001;65(2):232-60. https://doi.org/10.1128/MMBR.65.2.232-260.2001.

55. Bhalla K, Bhardwaj P, Gupta A, Mehra S, Nehra D, Nanda S. Role of epidemiological risk factors in improving the clinical diagnosis of streptococcal sore throat in pediatric clinical practice. J Fam Med Prim Care. 2019;8(10):3130-5. https://doi.org/10.4103/ffmpc.jfmpc_495_19.

56. Ba-Saddik I, Munibari A, Alhilali A, Ismail S, Murshed F, Coulter J, et al. Prevalence of group A beta-haemolytic Streptococcus isolated from children with acute pharyngotonsillitis in Aden, Yemen. Trop Med Int Health. 2014;19(4):431-9. https://doi.org/10.1111/tmi.12264.

57. Rimoin AW, Fischer Walker CL, Chitale RA, Hamza HS, Vince A, Gardovska D, et al. Variation in clinical presentation of childhood group a streptococcal pharyngitis in four countries. J Trop Pediatr. 2008:54(5):308-12.

\section{Publisher's Note}

Springer Nature remains neutral with regard to jurisdictional claims in published maps and institutional affiliations.

Ready to submit your research? Choose BMC and benefit from:

- fast, convenient online submission

- thorough peer review by experienced researchers in your field

- rapid publication on acceptance

- support for research data, including large and complex data types

- gold Open Access which fosters wider collaboration and increased citations

- maximum visibility for your research: over $100 \mathrm{M}$ website views per year

At $\mathrm{BMC}$, research is always in progress.

Learn more biomedcentral.com/submissions 